\title{
Designing the next generation of ocean iron fertilization experiments
}

\author{
Andrew J. Watson ${ }^{1, *}$, Philip W. Boyd ${ }^{2}$, Suzanne M. Turner ${ }^{1}$, Timothy D. Jickells ${ }^{1}$, \\ Peter S. Liss ${ }^{1}$ \\ ${ }^{1}$ School of Environmental Science, University of East Anglia, Norwich NR4 7TJ, UK \\ ${ }^{2}$ NIWA Centre for Chemical and Physical Oceanography, Department of Chemistry, University of Otago, PO Box 56, \\ Dunedin 9054, New Zealand
}

\begin{abstract}
The first generation of open-ocean iron enrichments (1993 to 2005) have all had broadly the same design. Enrichment of patches of ocean was typically on a $10 \mathrm{~km}$ length-scale, and experiments were of a duration of weeks. These scales were dictated by what could conveniently be achieved from research vessels, using tracers to track Lagrangian patches. The extrapolation of experimental findings to the larger scales required for carbon sequestration by ocean iron fertilization (OIF) leaves many uncertainties, to answer which, longer duration (i.e. months) and larger scale observations (100 to $200 \mathrm{~km}$ length-scale) are required. However, to extrapolate to a timescale of decades and to the scale of ocean basins, such observations must be conducted in parallel (and where possible assimilated into) detailed models of the physics and biogeochemistry of the fertilized waters. Our present understanding suggests that any carbon sequestration will occur as the net result of changes in the air-sea flux integrated over millions $\mathrm{km}^{2}$ and many years, and can only realistically be assessed by modelling. A central role of the observational studies will be to make such models as accurate as possible in their simulations and predictions. We present a scheme for the design of a second generation of ocean iron-enrichments and discuss the challenges that are evident in linking the modelling and observational components of such studies.
\end{abstract}

KEY WORDS: Carbon - Sequestration $\cdot$ Climate $\cdot$ Mitigation $\cdot$ Southern Ocean $\cdot$ HNLC $\cdot$ Nutrient . Chlorophyll

\section{UNANSWERED QUESTIONS FROM PREVIOUS RELEASES}

Open-ocean iron addition experiments (FeAXs) have been performed in each of the high-nutrient, lowchlorophyll (HNLC) regions of the World Ocean - the equatorial Pacific Ocean, Southern Ocean and north Pacific Ocean - and have established the fundamental role of iron limitation in all these regions (de Baar et al. 2005, Boyd et al. 2007). These experiments have all followed a similar design (Watson et al. 1991), in which patches on the order of $10 \mathrm{~km}$ long are initially seeded with both inorganic iron and the inert tracer sulphur hexafluoride, and the chemical and biological consequences of enrichment are followed over an ensuing period of several weeks. The time scale and conse- quently the spatial dimension of the experiments have been set by very practical concerns and logistical constraints; a campaign from even the largest research vessels can rarely last more than 2 mo. The endurance of the ships and the scale of funding available (not to mention the reluctance of scientists and seagoers to spend many months away from home) set this time scale. In turn, this means that patches reach only a few tens of $\mathrm{km}$ in length-scale before the studies end. Using 2 or more research cruises, recent experiments have increased the duration somewhat (e.g. Coale et al. 2004), but exercises such as the Southern Ocean Iron Experiments (SOFeX) and the European Iron Fertilization Experiment (EIFEX) (Hoffmann et al. 2006) are at the upper limit of what can be achieved by conventional oceanography. 
Though much has been learned from these experiments about the effects of iron addition at the ecosystem level, if we are interested in the effects of deliberate ocean iron fertilization (OIF) as a method for sequestration of carbon, or for that matter, in the climatic effects of increased iron availability on glacialinterglacial time scales, then we need to upscale our results to longer times and larger space scales. Difficulties quickly become apparent when this is attempted. Recent reviews (de Baar et al. 2005, Boyd et al. 2007) have summarized where our knowledge is still inadequate for this extrapolation and the major remaining questions are summarized in Table 1.

\section{HOW IS $\mathrm{CO}_{2}$ SEQUESTERED FROM THE ATMOSPHERE BY OIF?}

In order to understand the likely influences on the efficiency of sequestration, it is helpful to describe the carbon balance of a parcel of water that upwells into the surface layer of the ocean. Suppose we take some typical deep ocean water and bring it to the surface in an HNLC region - consider first the polar Southern Ocean or sub-antarctic. In the absence of iron fertilization, biological uptake of nutrients and carbon takes place, fixing carbon and macronutrients to the extent allowed by the iron (and light) availability. After some

Table 1. Major uncertainties in the effects of deliberate ocean iron fertilization

\begin{tabular}{|c|c|c|c|}
\hline Process & Issue & Finding & Comments \\
\hline \multirow[t]{5}{*}{$\begin{array}{l}\text { Carbon sequestration } \\
\text { efficiency }\end{array}$} & Carbon fixation in surface water & Variable $^{\mathrm{a}}$ & $\begin{array}{l}\text { Latitude, mixed layer depths }+ \text { light } \\
\text { co-limitation }\end{array}$ \\
\hline & Carbon export & None/little/significant ${ }^{\mathrm{b}}$ & Limited duration of studies \\
\hline & Depth of carbon export & Poorly constrained & \\
\hline & Duration of carbon sequestration & Unknown & Unanswerable by observations alone \\
\hline & Fraction fixed from atmosphere & Poorly known & $\begin{array}{l}\text { Likely unanswerable by observations } \\
\text { alone }\end{array}$ \\
\hline $\begin{array}{l}\text { Influence on } \\
\text { dissolved oxygen }\end{array}$ & $\begin{array}{l}\text { Formation of subsurface } \\
\mathrm{O}_{2} \text { minima }\end{array}$ & Poorly known ${ }^{\mathrm{c}}$ & $\begin{array}{l}\text { Potentially harmful, depth } \\
\text { dependent }\end{array}$ \\
\hline \multirow[t]{4}{*}{$\begin{array}{l}\text { Production of other } \\
\text { climate-active gases }\end{array}$} & Methane \& nitrous oxide & $\begin{array}{l}\text { No effect/possible } \\
\text { enhancement } t^{\mathrm{d}, \mathrm{e}, \mathrm{f}}\end{array}$ & Significant warming potential \\
\hline & Dimethylsulphide & No change/ increase ${ }^{b}$ & $\begin{array}{l}\text { Some evidence that enhancement } \\
\text { is transient }\end{array}$ \\
\hline & Biogenic halocarbons & $\begin{array}{l}\text { Reduction/no change/ } \\
\text { increase }^{g}\end{array}$ & $\begin{array}{l}\text { Pertinent to atmospheric oxidation } \\
\text { chemistry \& particle formation }\end{array}$ \\
\hline & $\begin{array}{l}\text { Biogenic hydrocarbons, } \\
\text { including alkyl nitrates }\end{array}$ & No change/increase $e^{e, g}$ & $\begin{array}{l}\text { Pertinent to atmospheric oxidation } \\
\text { chemistry \& particle formation }\end{array}$ \\
\hline \multirow{6}{*}{$\begin{array}{l}\text { Effects on ecosystems } \\
\text { and biogeochemistry }\end{array}$} & Phytoplankton species shifts & Mainly towards diatoms ${ }^{b}$ & Are shifts transient? \\
\hline & Mesozooplankton stocks & No change/increase ${ }^{b}$ & $\begin{array}{l}\text { Localised increases within Fe patch } \\
\text { due to arrested vertical migration: } \\
\text { duration of study \& longer } \\
\text { reproductive cycles }\end{array}$ \\
\hline & Higher trophic levels & Unknown & $\begin{array}{l}\text { Limited duration of studies. } \\
\text { Possibility of enhanced secondary } \\
\text { and higher-level production }{ }^{j}\end{array}$ \\
\hline & Macronutrient uptake & Small to significant ${ }^{b}$ & $\begin{array}{l}\text { Mixed layer depths + light } \\
\text { co-limitation }\end{array}$ \\
\hline & Reduction of nutrient transport & $\begin{array}{l}\text { Important in upwelling } \\
\text { regions }{ }^{\mathrm{h}}\end{array}$ & $\begin{array}{l}\text { Supply flows to other areas cut off, } \\
\text { e.g. sub-tropical gyres }\end{array}$ \\
\hline & Nutrient remineralization & $\begin{array}{l}\text { May affect global } \\
\text { distributions }\end{array}$ & $\begin{array}{l}\text { At present only evident from } \\
\text { modelling studies }{ }^{\mathrm{i}}\end{array}$ \\
\hline
\end{tabular}

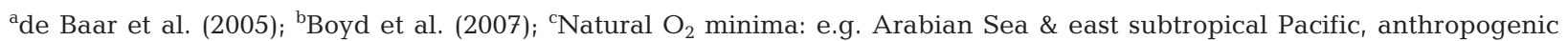

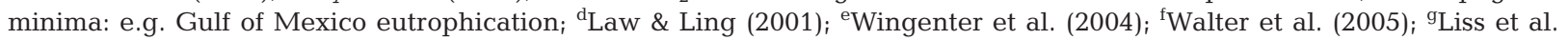
(2005), h Cooper et al. (1996); ${ }^{\mathrm{i}}$ Gnanadesikan et al. (2003); ${ }^{\mathrm{j} T}$ Tsuda et al. 2006 
period at the surface, which is typically of the order of 1 or 2 yr and probably depends very much on proximity to frontal regions, the water is subducted or transported by deep winter mixing out of the surface layer. As relatively cold, dense water, it can mix into the deep or intermediate waters and may not surface again for 100 s of yr. If we now imagine that this water is fertilized with iron while it is at the surface and that its $\mathrm{pCO}_{2}$ decreases as the iron-stimulated bloom develops, it will begin to take up atmospheric $\mathrm{CO}_{2}$, or to decrease the outgassing flux if the region is a net source of $\mathrm{CO}_{2}$ to the atmosphere. When this water is subducted, any $\mathrm{CO}_{2}$ it has removed from the atmosphere, or that it retains when, without fertilization, it would have been lost to the atmosphere, will be transported into the ocean's interior ocean and sequestered until that water is again brought to the surface.

It is notable that in this description the sequestration of carbon from the atmosphere is not dependent on having an export flux to any particular depth. Provided the biologically fixed carbon is not quickly respired back to $\mathrm{CO}_{2}$ while the water is still at the surface, sequestration could occur even if there were no export flux. The export flux is only important in that, since remineralization of the phytoplankton carbon is often quite fast (days, Boyd et al. 2004), export ensures that a proportion of this remineralization would occur at depths where the water is out of contact with the atmosphere. The important point is that the fertilized water has a limited residence time at the surface before subduction and that during this time fertilization induces enhanced lowering of its $\mathrm{pCO}_{2}$. Efficient sequestration will be dependent on this time scale. In particular, if the cumulative natural iron supply to this water (from the atmosphere, for example) is sufficient to cause the carbon fixation to occur in any case during the time it is at the surface, the deliberate iron fertilization is largely redundant; its only effect is to speed up by 1 or 2 yr a sequestration that would have occurred even without the artificial fertilization, focusing enhanced productivity into a bloom at the expense of reduced production in the waters downstream. The condition for efficient sequestration is therefore that the residence time at the surface, $\tau_{r}$, must satisfy:

$$
\tau_{\mathrm{e}}<\tau_{\mathrm{r}}<\tau_{\mathrm{Fe}}
$$

where $\tau_{\mathrm{e}}$ is the air-sea equilibration time for $\mathrm{CO}_{2}$, which is typically $1 \mathrm{yr}$ (Broecker \& Peng 1982) and $\tau_{\mathrm{Fe}}$ is the time that would be required for the natural iron flux to supply iron equivalent to that needed for the fertilization. This second time scale depends on poorly known variables, such as the C:Fe ratio assumed necessary for open ocean phytoplankton and (if the iron source is atmospheric dust) the solubility of the iron in aerosol. As an example, using figures from Jickells et al. (2005) for the iron flux to the Southern Ocean, a solubility of iron in dust of $3 \%$ (Baker \& Jickells 2006), a mixed layer depth of $50 \mathrm{~m}$ and a molar C:Fe ratio of $10^{5}$, we calculate a $\tau_{\mathrm{Fe}}$ of about $10 \mathrm{yr}$.

This discussion suggests that sequestration efficiency due to iron fertilization may be less in the equatorial Pacific, as models tend to show (e.g. Sarmiento \& Orr 1991, Cooper et al. 1996). Water that upwells into the surface layer in this region is strongly heated and therefore much less dense than most subsurface water, and it is unlikely to be permanently subducted below the thermocline until it has been transported to cooler regions, requiring decadal or longer residence time at or near the surface. This residence time will usually exceed $\tau_{\mathrm{Fe}}$ (which in most regions is shorter than that calculated for the Southern Ocean, since the atmospheric iron flux is at its lowest in polar waters). The net effect of OIF in such warm water regions would then be simply to replace the slow uptake of macronutrients and carbon that would normally take place over a period of years after the water has upwelled with an artificially induced bloom. Alternatively, recent models suggest some subduction to comparatively shallow depths may occur from the equatorial Pacific (F. Chai pers. comm.). In that case, fertilization here would provide some sequestration, though of a less permanent nature than in the sub-antarctic. In the sub-arctic Pacific some intermediate water (North Pacific Intermediate Water) is formed and efficient sequestration might be possible if waters feeding into this water mass were fertilized.

This description should make clear why realistic physical-biogeochemical modelling of a given OIF event must be an intrinsic part of any strategy to investigate the sequestration of carbon. The $\mathrm{C}$ sequestered cannot be measured by any simple means. It is certainly not equal to the export flux deriving from a bloom triggered by the fertilization, for example. Rather, it is the difference between the net air-sea flux of carbon dioxide due to the iron fertilization and that which would have occurred in its absence. Calculation of this flux involves integration over periods of years and an area of ocean that rapidly grows to cover millions of $\mathrm{km}^{2}$. Clearly this can only be determined by modelling. The problem is that the model must correctly simulate the physics, chemistry and biology, and their interplay in such HNLC open-ocean provinces. But our models are not currently this good. The best we can do is likely to be to guide, improve and make more accurate the models by well-chosen measurements, not only of inorganic carbon but of all the relevant variables that we can measure. Thus, we see the program as being a joint effort of modellers and field experimentalists, with the observational program improving the models by validating any variable that 
can be both modelled and measured. Observations alone cannot determine the carbon sequestration and models should not be believed unless they consistently reproduce observations.

\section{NEED FOR A JOINT MODELLING- OBSERVATIONAL STRATEGY}

It is clear that to reduce the uncertainties about the effects of iron fertilization, observations on scales larger than used those up to now are needed, and we assume here that the initial fertilization in Generation 2 experiments would be on the order of $200 \times 200 \mathrm{~km}$. However, as discussed in the previous section, it is evident that observations alone are insufficient. Rather, we need a joint modelling-observational strategy, because there are several crucial questions that direct observation alone cannot answer, as follows: (1) The outcome of the release, including its eventual efficiency at removing carbon from the atmosphere, will be strongly dependent on the initial physical, chemical and biological conditions at the potential site. These will vary with location and also with factors such as mixed-layer depth, proximity to oceanic fronts and degree of eddy activity. Assessment of all these will require models resolving eddies and fronts (typically the model resolution should be less than $10 \mathrm{~km}$ ). (2) The assessment of the lateral trajectory of the iron patch also requires assimilating remote sensing and in situ observations into eddy resolving models, which will constrain the initial conditions of physical, biological and chemical state, as well as keep the modelled physics realistic. (3) Assessment of these outcomes will require integration up to scales that are too large and long for any ship-based observation programme. (4) Finally, this assessment requires evaluation of the 'control' case - what would have happened in the absence of a release - which can be provided by observations of a site within the surrounding HNLC waters for small experiments, but only by a model for larger experiments.

Model studies would need therefore to be carried out before, during and after a given FeAX. Adequately integrating such detailed model simulations with an observational program is likely to be as challenging as the practical logistics of the experiment at sea.

\section{SITE SELECTION}

In the first generation of experiments, the criteria for site selection were appropriate biogeochemical conditions (HNLC, low iron, iron-limited phytoplankton, seasonal mean mixed layer depth) and relatively quiescent physical conditions (to permit a coherent labelled patch of ocean to persist). For larger experiments that rely less on tracking a tracer, this basis for site selection will no longer be so relevant. Modelling should be used to help select the site, considering not just the large-scale dynamics (e.g. what part of the world ocean to do the release in) but also the mesoscale: proximity to fronts, eddy scales and kinetic energy. For this purpose, high resolution models and observations (from satellite altimetry, for example) would be useful and could help determine the best strategy for the iron release. The 'confined patch' strategy used up until now may well not be the best way to begin a larger and longer-scale experiment (see later), which might be better initiated by an elongated streak.

\section{DESIGN OF THE OBSERVATIONAL PHASE OF THE EXPERIMENT}

Following the selection of a suitable site based on an ensemble of model simulations, the next step is to design a comprehensive survey of the variability exhibited by the properties that may be altered by the iron release. This survey should cover both the waters upstream (i.e. into which the iron will eventually be released) and downstream (i.e. the waters that will interact with the labelled iron patch as it evolves). The variables to be measured would include biogenic gases, downward export flux, biological productivity and nutrients. The areal extent of this survey will be dictated by the expected final areal extent of the iron release. Modelling will also be essential to provide some constraints on the probable trajectory (e.g. Coale et al. 1996) and evolution (dilution rate) of the ironlabelled patch over the subsequent 6 to 12 mo.

During the first generation of experiments, around 12 to $14 \mathrm{~h}$ was required to add the dissolved iron so that it formed a coherent patch of $10 \mathrm{~km}$ length-scale. However, logistics dictate that for iron enrichment of a $200 \times 200 \mathrm{~km}$ patch, multiple vessels would be required if a coherent enrichment patch is to be accomplished within a few days. Such a challenge would require making the iron addition in a carefully co-ordinated manner, which would involve monitoring a suite of Lagrangian (i.e. moving with the net flow of the upper ocean currents, etc.) drifters both in surface and subsurface waters (the latter ensuring the water at depth below the patch is moving in concert with the iron-enriched surface layer). A possible alternative to iron addition using multiple ships might be to use aircraft to spread the iron, though this would inevitably mean the iron would be added at the very surface, rather than homogenized into the mixed layer. We also foresee some operational difficulties in spreading $>10 \mathrm{t}$ of material from the air in remote regions of the ocean. 
Previous experiments have used the conservative chemical tracer sulphur hexafluoride as a proxy for the concurrently added iron (Watson et al. 1991); however, the use of such a tracer, which is a powerful approach, is impractical on larger spatial scales because the lifetime of the tracer in the surface water is too short and mapping a large patch would take too much ship time. It might be possible to label the centre of this $200 \mathrm{~km}$ long patch (and if multiple vessels were adding the iron, this might be very useful), but mapping a patch this large as it evolves would require other approaches including aircraft or helicopters with bio-optical sensors to monitor chlorophyll fluorescence or $\mathrm{CO}_{2}$ (Boyd et al. 2007). As the patch evolved onto larger scales, satellite remote-sensing could be used to assess its areal extent, as was done on some of the first generation iron enrichments at scales of 500 to $1000 \mathrm{~km}^{2}$ (Boyd et al. 2007).

The first set of iron enrichments made very wideranging ancillary measurements over and above the core physical, chemical and biological approaches. Generation 2 experiments will no doubt do likewise, but discussion of the full suite of measurements is beyond the scope of this short commentary. In Table 2 we present examples of approaches that provide data streams of different resolution, from remotely sensed to discrete measurements. As data assimilation into models is advocated as part of this multi-stranded experimental design, resolving how best to assimilate a range of datasets with different characteristics (frequency of observations, data quality) requires considerable thought and development, as do issues of free parameter space versus computation needs for conducting eddy resolving physical-biogeochemical model simulations.

\section{EVOLUTION OF THE IRON-STIMULATED BLOOM}

Previous experience during earlier FeAXs suggests that monitoring the latter stages of the bloom (i.e. after it terminates due to resource limitation) and the fate of the algal carbon are problematic. The main issue here is that much of the export, transformation and recycling of this algal carbon takes place in the waters underlying the surface layer that was initially ironenriched. Hence the need for Lagrangian drifters in the surface and subsurface layers and some means to ensure that there is no lateral slippage between these layers, as is sometimes observed (Savidge et al. 1992), that would uncouple the processes occurring in each layer. Other important issues include defining the depth of carbon sequestration and the areal extent of the source region for particles settling out of the surface ocean (the so-called 'statistical funnel') and how it compares areally with that of the iron-enriched patch (Siegel et al. 2008). A further challenge at this time will be tracking the fate of the dissolved constituents of the bloom signature (i.e. after recycling by microbes and zooplankton). Some of these are climate-reactive gases with very high greenhouse warming potential (see Law 2008, this Theme Section), which could potentially offset the effects of $\mathrm{C}$ storage resulting from the bloom. This challenge becomes greater with a longer

Table 2. Sampling resolution of techniques used to obtain measurements of properties prior to, during, and after an FeAX. Range of datasets will pose problems for assimilating observations into a model that will be used to investigate the longer-term (decades) fate of the FeAX. Due to the large number of techniques used on the first generation of experiments, here we provide a small subset of techniques and properties. T: temperature; S: salinity; LIDAR: light detection and ranging; DMS: dimethylsulfide; DMSP: dimethylsulphoniopropionate. Note, in some cases analysis of samples-e.g. thorium for high-resolution estimates of export fluxes - would take months

\begin{tabular}{|c|c|c|c|}
\hline Approach & Technique & Property & Temporal resolution \\
\hline \multirow[t]{4}{*}{ Remote-sensing } & Glider & $\mathrm{T}, \mathrm{S}, \mathrm{O}_{2}$, nutrients, particle optics & Hours \\
\hline & Instrumented buoy & $\mathrm{T}, \mathrm{S}, \mathrm{O}_{2}$, bio-optics, particle optics & $10 \mathrm{~s}$ of $\min$ \\
\hline & Satellite & Chlorophyll, eddies (altimetry), temperature & Daily images \\
\hline & Airborne LIDAR & Chlorophyll, photosynthetic competence & Min \\
\hline \multirow[t]{2}{*}{ Vessel-underway survey } & Undulating tow-body & Chlorophyll, nutrients & Min \\
\hline & Pumped seawater supply & $\begin{array}{l}\text { Biogenic gases (e.g. DMS, } \mathrm{CO}_{2} \\
\mathrm{CH}_{4} \text { \& DMSP), dissolved iron }\end{array}$ & Min \\
\hline \multirow[t]{2}{*}{ Vessel-discrete measurements } & CTD vertical profiles & $\mathrm{T}, \mathrm{S}$, chlorophyll & Hours \\
\hline & Water bottles/net tow & $\begin{array}{c}\text { Water samples for } \mathrm{N}_{2} \mathrm{O} \text {, phytoplankton } \\
\text { (microscopy), grazing (experiments), } \\
\text { thorium (export) }\end{array}$ & $6 \mathrm{~d}^{-1}$ \\
\hline Moored instrumentation & Sediment traps & $\mathrm{C}$ export and $\mathrm{C}$ sequestration & measurement $2-3 \mathrm{~d}^{-1}$ \\
\hline
\end{tabular}


experiment because of the impact of ocean currents/ physical transports in diluting these signals as the patch gets larger. There is also the added difficulty of detecting such by-products of the decaying algal bloom over the background variability in these downstream waters (hence the need for some downstream survey before commencing the initial iron release).

The logistical challenges in an experiment such as we describe are formidable. They include the need for multiple ships (for the pre-release survey, experiment and post-bloom monitoring). This will necessitate the frequent replacement of vessels (occupation of a site for longer than $2 \mathrm{mo}$ is not possible, as mentioned earlier) and the associated standardization and intercalibration exercises required to ensure uniformity during multiple vessel occupations. Besides using multiple ships for surveying the iron patch and adjacent areas, the emerging autonomous ocean sampling techniques should be used for monitoring and surveying processes inside the iron patch. For example, a set of sophisticated robotics vehicles (autonomous underwater vehicles, gliders and floats) equipped with optical and chemical sensors (Riser \& Johnson 2008) will be useful not only to provide 3-dimensional distribution of physical and biogeochemical properties during initial release of iron and onset of phytoplankton bloom, but also for following the iron patch and detecting the decreasing signature of enhanced carbon production for months after the initial addition (Bishop et al. 2002). Finally, there will be a time lag in getting samples and data analysed and in ensuring quality control, prior to assimilation into the model.

A high-resolution eddy-resolving model, preferably guided by assimilation of real-time data, would be used to guide and simulate the release and the first phase of observations. It could be used to interpret the data being returned and to assess how representative the measurements taken at any one point are, which will be particularly important given that it will not be possible to obtain comprehensive observational coverage of the large area to be monitored using in situ measurements. Through near real-time iterations between observations and the model, it may be possible to command robotic vehicles to locales where their data will be most useful for assessing water and carbon movement. Finally, the model could be run forward after the main observation phase has ended, to predict the probable long term effects.

\section{CONCLUSIONS}

It is evident that to conduct a second generation of experiments on the scales needed to address the issue of the utility of carbon sequestration and monitoring of unintended side effects, a step increase in the scale of developmental work, costs, lead-in time, co-ordination and logistics will be necessary. We advocate a joint modeling-observational approach as the only means to conduct these second-generation studies. However, even at this early stage of development, it is clear that linking a wide range of measurements, many made on disparate time and/or spatial scales with models (via data assimilation) will be problematic. It may be necessary to use some of the observational results from the first generation of iron fertilization experiments to develop and improve physical-biogeochemical models (Fujii et al. 2005, Chai et al. 2007).

Modelling studies based on results from the first generation of studies point to the complex interplay of physics, photochemistry and biology in setting the concentrations of biogenic gases such as DMS (Le Clainche et al. 2006). It is not possible to have this level of detail in the regional or basin-scale circulation models needed to assimilate observations from the experiments, so a variety of different types of model studies will be necessary to fully interpret the experiments.

Modellers may be horrified by the faith that we are apparently placing in their codes. They will point out that the state of our knowledge is currently insufficient to place much confidence in their predictions and that different models presently give substantially different pictures of the effect of iron fertilization. Nevertheless, this is the state of our knowledge at the present: in this complex area the models represent our best synthesis of current understanding and the outcomes that they agree on are the only ones for which we can claim any certainty.

The program we advocate is a formidable challenge. However, it does not necessarily all have to be achieved in a single, massive effort. Many of the steps on the road to such a project are happening already-e.g. improvements in models, observational techniques and data assimilation methods. Implementation of secondgeneration iron fertilization experiments will become progressively more tractable in the coming years as we make progress in these related fields. The major challenge will then be to integrate all of these advances into a coherent program at the large scales necessary for the next generation of experiments.

Acknowledgements. We thank F. Chai and K. Buesseler for helpful reviews that enabled us to improve this paper.

\section{LITERATURE CITED}

Baker AR, Jickells TD (2006) Mineral particle size as a control on aerosol iron solubility. Geophys Res Lett 33:L17608

Bishop JKB, Davis RE, Sherman JT (2002) Robotic observations of dust storm enhancement of carbon biomass in the North Pacific. Science 298:817-821

Boyd PW, Law CS, Wong CS, Nojiri Y and others (2004) The 
decline and fate of an iron-induced subarctic phytoplankton bloom. Nature 428:549-553

Boyd PW, Jickells T, Law CS, Blain S and others (2007) Mesoscale iron enrichment experiments 1993-2005: synthesis and future directions. Science 315:612-617

Broecker WS, Peng TH (1982) Tracers in the sea. Eldigio Press, New York

Chai F, Jiang MS, Chao Y, Dugdale RC, Chavez F, Barber RT (2007) Modeling responses of diatom productivity and biogenic silica export to iron enrichment in the equatorial Pacific Ocean. Global Biogeochem Cycles 21:GB3S90

Coale KH, Johnson KS, Fitzwater SE, Gordon RM and others (1996) A massive phytoplankton bloom induced by an ecosystem-scale iron fertilization experiment in the equatorial Pacific Ocean. Nature 383:495-501

Coale KH, Johnson KS, Chavez FP, Buesseler KO and others (2004) Southern ocean iron enrichment experiment: carbon cycling in high- and low-Si waters. Science 304:408-414

Cooper DJ, Watson AJ, Nightingale PD (1996) Large decrease in ocean-surface $\mathrm{CO}_{2}$ fugacity in response to in situ iron fertilization. Nature 383:511-513

de Baar HJW, Boyd PW, Coale KH, Landry MR and others (2005). Synthesis of iron fertilization experiments: from the Iron Age in the Age of Enlightenment. J Geophys ResOceans 110:C09S16

Fujii M, Yoshie N, Yamanaka Y, Chai F (2005): Simulated biogeochemical responses to iron enrichments in three high nutrient, low chlorophyll (HNLC) regions. Prog Oceanogr 64:307-324

Gnanadesikan A, Sarmiento JL, Slater RD (2003) Effects of patchy ocean fertilization on atmospheric carbon dioxide and biological production. Global Biogeochem Cycles 17: 1050

Hoffmann LJ, Peeken I, Lochte K, Assmy P, Veldhuis M (2006) Different reactions of Southern Ocean phytoplankton size classes to iron fertilization. Limnol Oceanogr 51:1217-1229

Jickells TD, An ZS, Andersen KK, Baker AR and others (2005) Global iron connections between desert dust, ocean biogeochemistry, and climate. Science 308:67-71

Submitted: February 7, 2008; Accepted: April 9, 2008
Law CS (2008) Predicting and monitoring the effects of largescale ocean iron fertilization on marine trace gas emissions. Mar Ecol Prog Ser 364:283-288

> Law CS, Ling RD (2001) Nitrous oxide flux and response to increased iron availability in the Antarctic Circumpolar Current. Deep-Sea Res II 48:2509-2527

Le Clainche Y, Levasseur M, Vézina A, Bouillon RC and others (2006) Modeling analysis of the effect of iron enrichment on dimethyl sulfide dynamics in the NE Pacific (SERIES experiment). J Geophys Res 111:C01011

> Riser SC, Johnson KS (2008) Net production of oxygen in the subtropical ocean. Nature 451:323-325

Sarmiento JL, Orr JC (1991) 3-dimensional simulations of the impact of Southern Ocean nutrient depletion on atmospheric $\mathrm{CO}_{2}$ and ocean chemistry. Limnol Oceanogr 36: 1928-1950

Savidge G, Turner DR, Burkill PH, Watson AJ and others (1992) The BOFS 1990 Spring Bloom experiment: temporal evolution and spatial variability of the hydrographic field. Prog Oceanogr 29:235-281

Siegel DA, Fields E, Buesseler KO (2008) A bottom-up view of the biological pump: modeling source funnels above ocean sediment traps. Deep-Sea Res I 55:108-127

Tsuda A, Saito H, Nishioka J, Ono T, Noiri Y, Kudo I (2006) Mesozooplankton response to iron enrichment during the diatom bloom and bloom decline in SERIES (NE Pacific). Deep-Sea Res II 53:2281-2296

Walter S, Peeken I, Lochte K, Webb A, Bange HW (2005) Nitrous oxide measurements during EIFEX, the European Iron Fertilization Experiment in the subpolar south Atlantic Ocean. Geophys Res Lett 32:L23613.1-L23616.4

Watson A, Liss P, Duce R (1991) Design of a small-scale in situ iron fertilization experiment. Limnol Oceanogr 36: 1960-1965

Wingenter OW, Haase KB, Strutton P, Friederich G, Meinardi S, Blake DR, Rowland FS (2004) Changing concentrations of $\mathrm{CO}, \mathrm{CH}_{4}, \mathrm{C}_{5} \mathrm{H}_{8}, \mathrm{CH}_{3} \mathrm{Br}, \mathrm{CH}_{3} \mathrm{I}$, and dimethyl sulfide during the southern ocean iron enrichment experiments. Proc Natl Acad Sci USA 101:8537-8541

Proofs received from author(s): June 25, 2008 